\section{Paz abundante}

Por John Stevens

Barcelona: Editorial Kairós, 2005

144 páginas. $18,5 \times 24,5 \mathrm{~cm}$. Ilustraciones

I.S.B.N.: $84-7245-415-0 \bullet 15 €$

Disponible en:

Editorial Kairós

C/ Numancia, 117-121

08029 Barcelona (España)

Telf.: +34 4949440

Fax: +34 4105166

E-mail: info@editorial.com

http://www.editorialkairos.com

\section{Revisión por José Santos Nalda Albiac}

John Stevens vuelve a relatarnos en estas páginas, con mas detalles y anécdotas si cabe -aunque no sin cierta reiteración respecto a otros de sus libros-, la vida del fundador del Aikido Morihei Ueshiba, contemplando su trayectoria desde tres puntos de vista: 1.- El hombre (su vida). 2.- El maestro (su enseñanza). 3.- El mensaje (el espíritu y la filosofía del Aikido).

En la primera parte, cuantitativamente la más extensa de la obra, el autor realiza un repaso biográfico de aquellos hechos más destacados de la vida de Ueshiba, analizando en detalle el conjunto de influencias, acontecimientos y vivencias que fueron configurando la personalidad de este extraordinario personaje. Página a página, Stevens narra el camino del fundador del Aikido hacia la espiritualidad -lo cual no quiere decir que no tuviese rasgos "muy humanos", como su famoso mal genio, que el autor cita en numerosas ocasiones- $y$ hacia el reconocimiento social, circunstancia que llegaría a su apogeo en 1964 -entonces tenía 81 años de edad-cuando fue condecorado por el Emperador de Japón, junto a Kyuzo Mifune, quizá la figura más importante del judo tradicional en aquella época.

La segunda parte del libro contempla a Ueshiba como maestro de artes marciales. Según las palabras del autor, era considerado como uno de los más destacados expertos de su tiempo, a juicio de las hazañas documentadas que realizó en múltiples ocasiones.

Stevens relata que Ueshiba se inició en el Sumo, y más tarde, en el ejército, se familiarizó en el manejo de las armas de fuego y las tácticas occidentales, alcanzando gran habilidad en el combate a bayoneta, del que desarrolló el concepto de "Irimi". Su formación en los estilos de artes marciales tradicionales también fue muy importante, recibiendo instrucción en un gran número de escuelas como la Goto Ryu Yagyu Jujutsu, Daito Ryu, Kuki Shin Ryu, Take no Uchi Ryu, Kito Jujutsu Ryu, Hozoin Ryu, Yagyu Ryu o la Katori Shinto Ryu. A pesar de sus frecuentes viajes a China, nunca se interesó por las artes marciales de aquél país, ni siquiera por el popular Tai-Chi.

El arte marcial creado por Ueshiba en Ayabe, recibió el nombre de Daito Ryu Aiki Jutsu, mas tarde en Tokio se denominó Kobukan Aiki Budo, Ueshiba Ryu Jutsu, Tenshin Aiki Budo, y en 1942 , Aikido.

Como artista marcial, poseía una gran intuición para asimilar y transferir sus conocimientos a todo tipo de arte marcial, aunque no lo hubiera practicado nunca, y afirmaba que los dioses le inspiraban las técnicas que enseñaba. Sus discípulos cuentan que poseía un sexto sentido, gracias al que podía adivinar las intenciones hostiles o agresivas de sus interlocutores. En 1933 publicó un libro titulado Budo Renshu. En dicho manual se encuentran un buen número de "Dokas" o poemas didácticos que completaban su instrucción técnica, como por ejemplo:

"El Budo verdadero es para el amor a la paz y la armonía. Entrenaos diariamente para manifestar este espíritu por todo el mundo".

En varias épocas de su vida permitió que filmasen sus clases y sus demostraciones, y en ellas podemos apreciar su arte inimitable, tanto en el apogeo de su vida como en los últimos años.

Por último, abordamos la tercera parte del libro que se ocupa del mensaje que este hombre quiso transmitir a todos aquellos que se interesasen por el Aikido. De la lectura de su vida podemos ver que era un inconformista, no satisfecho con la habilidad técnica y la fuerza física como medios u objetivos a perseguir en la práctica de un arte marcial, y buscaba el verdadero sentido del Budo mediante la introspección, el autocontrol, los ritos místicos y las plegarias a los dioses, o "kamis".

Nunca se interesó por el Zen, aunque otros estudiosos como el Dr. D.T. Suzu- ki, denominasen al Aikido como "el zen en movimiento", dado que la trayectoria original seguida por Ueshiba, inspirada e influenciada por la doctrina Omoto-Kyo, tiene pocas cosas en común con el Zen o el Budismo. Su enseñanza tenía por base las relaciones del hombre con las divinidades Shinto, los mitos del "Kojiki" o crónicas del Japón antiguo, y las teorías del Kotodama para explicar el origen del Universo

El Aikido era la Vía Sagrada que le habían revelado los Kamis, y que conduce a la paz y la armonía con el Universo, dada la supremacía de las fuerzas espirituales sobre las físicas. Como él mismo señalaba:

"El entrenamiento diario de Aikido permite que vuestra divinidad interior brille mas y mas....".

"Yo enseño este arte a mis estudiantes para que aprendan cómo ayudar a sus compañeros en la tierra".

Leyendo los textos sobre sus enseñanzas, podemos vislumbrar los fundamentos espirituales y filosóficos sobre los que Ueshiba quiso establecer el Aikido como Vía de realización personal. Encontramos párrafos de difícil comprensión, y otros más al alcance del aikidoka como son los siguientes:

"El Aikido es el principio de la no resistencia, y como no resiste, es victorioso desde el principio...".

"Por encima de todo uno debe unir su propio corazón con el de los dioses. Si uno no se une a Dios, el Universo no se puede armonizar...".

"En el auténtico Budo no hay enemigos, el auténtico Budo es una función de amor. No es para matar, ni para luchar, sino para ayudar a todos los seres y llevarles a su realización...”.

Para el lector de este libro tal vez hubiera sido más provechoso que el autor hubiera dedicado menos páginas a relatar la vida de Ueshiba como hombre, y hubiese sido más prolijo y clarificador al exponer el mensaje del fundador de este arte genial, ya que este mensaje sigue siendo objeto de estudio y debate entre sus seguidores. 
Como resumen, y a modo de conclusión, bien pudiera decirse que el objetivo deseado por Ueshiba para todos los practicantes es que aprendan a sofocar la violencia en su nacimiento, en sí mismos, a buscar la paz y establecer la armonía, cada uno en su entorno habitual, y ser capaces de vencer toda oposición y hostilidad con las armas del amor, el perdón, la comprensión y la concordia.

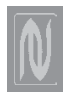

\section{Kárate superior 3. Kumite I \\ Kárate superior 4 . Kumite 2}

Por Masatoshi Nakayama

Madrid: Ediciones Tutor, 2005

143 y 144 páginas respectivamente. $17 \times 24$ $\mathrm{cm}$. Ilustraciones

I.S.B.N.: 84-7902-547-6, 84-7902-548-4 •

$12 €$ cada volumen

Disponible en:

Ediciones Tutor

C/ Marqués de Urquijo, 34, $2^{\circ}$ Izda

28008 Madrid (España)

Telf.: +34915599832

Fax: +34915410235

E-mail: info@edicionestutor.com

http//www.edicionestutor.com

\section{Revisión por Juan María García Díez}

Continuando con la nueva edición de la obra Kárate Superior, ediciones Tutor nos presenta dos nuevos ejemplares de la misma, dedicados íntegramente al tratamiento del Kumite (combate).

La primera aproximación a estos dos volúmenes nos refleja una evidente distinta forma de concebir un texto didáctico relativo a una disciplina de combate, tal y como es el Kárate, haciéndonos partícipes de todo un legado personal sobre los instructores que aparecen en esta nueva entrega de Kárate Superior. Es palpable el deseo del Maestro Nakayama de plasmar en estos dos volúmenes, dedicados al Kumite, una especie de reconocimiento hacia las personas que desarrollan las diferentes técnicas que se detallan a lo largo de sus páginas, haciendo que el lector acabe inevitablemente agradecido de tener, en tan sólo dos ejemplares, referencias de los más grandes instructores de la Asociación Japonesa de Kárate.

Las imágenes tomadas en estos dos libros, lejos de pertenecer a un estudio detallado de retoque fotográfico dirigido a reflejar la perfección de los gestos deportivos, van más allá al situarse en escenas tomadas a velocidad real de combate (la mayoría de ellas), ilustrando con un original enfoque lo que debe ser un texto dedicado a la aplicación práctica de las técnicas de Kárate. Está claro que no se busca la estética ficticia, sino que la realidad de las imágenes captadas ayuda al lector, de mejor forma, a la comprensión del mensaje contenido en las ilustraciones. Realmente, en este caso, una imagen vale más que mil palabras.

Al hilo de lo anteriormente expuesto, el practicante de Kárate que busque en esta parte de la obra del Maestro Nakayama un manual detallado para el aprendizaje básico de las técnicas de Kumite, no se halla en el mejor camino. No se trata en estos volúmenes de aportar un manual de base para el aprendizaje ni de proceder a un escalonamiento del mismo a través de técnicas de Kárate. El valor intrínseco de Kumite 1 y Kumite 2 reside en su aspecto documental, además de su innegable estética artística.

De este modo, en Kumite 1, los nombres de Maestros de la talla de Oishi, Takahashi, Lida, Ueki, Tsuyama, Asai o Kanazawa hacen del estudio de las imágenes un auténtico placer para el lector. Cada Maestro, instructor de alto nivel de la Asociación Japonesa de Kárate, detalla sus técnicas favoritas en combate a la vez que, en la presentación de cada uno de ellos, se enumeran una serie de factores y cualidades a tener en cuenta para la ejecución de las distintas técnicas que se describen.

Explicaciones acerca del trabajo de anticipación (Sen no Sen), la toma subsiguiente de la iniciativa (Go no Sen), ataques indirectos y de pierna en combate a corta distancia, tipos de patadas o el ataque a dos niveles conforman el contenido de este volumen de Kumite 1.

En el segundo de los libros, Kumite 2, la presencia de otro buen número de instructores de élite de la Japan Karate Association, entre los cuales figuran los Maestros Enoeda, Yamaguchi, Tanaka, Shoji, Omura, o los más recientes demostradores de la Asociación como los Maestros Osaka, Kawazoe o Yahara entregan al lector un apasionante y completo legado sobre las técnicas más efectivas del combate de Kárate.

Como colofón a todo este elenco de auténticas leyendas vivientes de la Asociación Japonesa de Karate, se suma, al final del volumen Kumite 2, la presencia del autor, Masatoshi Nakayama, ejecutando sus técnicas de combate favoritas: las paradas definitivas con kime. Antes de su fallecimiento, el maestro Nakayama nos aportó con esta obra una clara idea sobre el significado práctico del Kárate.

No se debe buscar en esta parte de la obra Kárate Superior un acercamiento a la aplicación de las técnicas de Kárate a la defensa personal tradicional, si bien el Maestro Nakayama era un consumado experto en las mismas, sino un tratado sobre el combate de Kárate y su diferente tipología, entendida dentro de unos márgenes de Kárate tradicional y dejando a un lado el combate deportivo reglamentado o Shiai Kumite.

Los dos volúmenes aportan además una serie de citas pertenecientes a textos antiguos, relativos a las artes marciales, tales como Fudochi shinmyoroku (Misterios de la sabiduría inmóvil), de Takuan Zenji; Heiho kadensho (La espada y la mente), de Yahyu Munenori; el célebre Gorin no sho (Libro de los cinco anillos), de Miyamoto Mushashi o Ittosai sensei kenpo sho (El método de la espada del Maestro Ittosai), de Kotoda Yahei.

Estos textos se añaden con la intención de ayudar al lector y practicante de artes marciales a una mejor comprensión del espíritu y actitud mental necesaria para la aplicación de las técnicas aprendidas y su transferencia hacia los distintos niveles de combate.

De igual manera, aparecen recogidos al comienzo de ambos tomos los conceptos imprescindibles en la realización del jyu kumite (combate libre). Esquemáticamente, se definen los puntos relativos a la postura del tren superior (Kamaekata), la forma de las posiciones (Tachikata), la fijación y aplicación de la mirada (Me no tsukekata), la distancia en el combate (Maai), dejando el tratamiento acerca del momento psicológico para ejecutar la técnica en último lugar (Waza o hodokosu koki).

Esta parte de la obra del Maestro Nakayama es un regalo de instantáneas llenas de vida y de mensajes de aplicación de las técnicas de Kárate tradicionales. Kumite 1 y Kumite 2 son, sin lugar a dudas, Kárate en estado puro. 